\title{
Entre distopia, realismo mágico e ficção científica: o problema do gênero no roteiro cinematográfico não filmado inédito de $A$ hora dos ruminantes
}

\author{
Between Dystopia, Magic Realism and Science \\ Fiction: The Problem of Genre in the Unfilmed \\ and Unpublished Screenplay of The Plague of the \\ Ruminants
}

\section{Marcelo Cordeiro de Mello ${ }^{1}$}

DOI: $10.19177 /$ memorare.v8e1202193-106

\begin{abstract}
Resumo: Este artigo apresenta ao leitor o projeto cinematográfico não filmado de $A$ hora dos ruminantes, de 1967, adaptado da obra homônima do escritor José J. Veiga pelo cineasta Luiz Sergio Person e o crítico de cinema e roteirista Jean-Claude Bernardet. Discutimos o problema do gênero a partir da relação com o tema da distopia, e analisamos a relação de $A$ hora dos ruminantes com dois gêneros artísticos: a ficção científica e o realismo mágico. A partir dessa discussão, e da análise de documentos inéditos sobre o projeto cinematográfico, levantamos a hipótese de que $A$ hora dos ruminantes poderia ter inaugurado um novo gênero cinematográfico híbrido.

Palavras-chave: Distopia. Ficção científica. Realismo mágico.
\end{abstract}

\begin{abstract}
This article introduces the reader to the unfilmed cinematographic project of The plague of the ruminants, of 1967, adapted from the literary work of the same name by writer José J. Veiga by filmmaker Luiz Sergio Person and film critic and screenwriter Jean-Claude Bernardet. We discuss the problem of film genre from its relationship with the theme of dystopia, and we analyze the connection of The plague of the ruminants with two artistic genres: science fiction and magic realism. Departing from this discussion, and the analysis of unpublished documents about this cinematographic project, we raise the possibility of The plague of the ruminants having inaugurated a new and hybrid cinematographic genre.
\end{abstract}

Keywords: Dystopia. Science fiction. Magic realism.

\footnotetext{
1 Doutor em Estudos Literários pela Universidade Federal de Minas Gerais (2019). Mestre em Literatura Portuguesa pela Universidade Paris IV, Sorbonne (2011). Graduado pela Universidade de Brasília: Bacharel em Letras Português (2007) e Licenciado em Francês (2013). Tem experiência na área de Letras, com ênfase em Língua e Literatura. Lecionou Língua portuguesa e respectiva literatura na Faculdade Evangélica de Brasília e no Liceu Francês de Brasília (2012-2014). Atuou como Assistente de Língua Portuguesa da Academia de Bordeaux, França (2010-2011). Foi Leitor de Língua Portuguesa da Universidade de Bourgogne, França (2008-2010). marcelocmello@gmail.com
} 


\section{Apresentação}

Em 1967, o cineasta Luiz Sergio Person e o crítico e roteirista JeanClaude Bernardet iniciam o projeto cinematográfico de $A$ hora dos ruminantes, baseado na obra homônima do autor goiano José J. Veiga. Embora o filme não tenha sido realizado, é possível retraçar sua gênese a partir de alguns documentos, especialmente o roteiro, do qual existem cópias depositadas nos acervos da Cinemateca Brasileira, em São Paulo, e da Cinemateca do Museu de Arte Moderna, no Rio de Janeiro. A pasta de $A$ hora dos ruminantes na Cinemateca Brasileira contém também alguns papéis de trabalho que permitem reconstituir este interessante projeto cinematográfico. 0 filme de $A$ hora dos ruminantes teria se destacado no panorama do cinema brasileiro daquela época, prenunciando uma estética alegórica que se afirmaria a partir dos anos 1970 - geralmente entendida como uma reação ao contexto político, na medida em que a alegoria permitia contornar as restrições da censura política imposta pela Ditadura Militar. Nossa pesquisa é a primeira a se debruçar sobre o roteiro cinematográfico de $A$ hora dos ruminantes este importante documento da cultura brasileira, que talvez tivesse inaugurado um novo gênero cinematográfico brasileiro.

Quando foi publicado, em 1966, o livro de José J. Veiga foi amplamente lido pela crítica como uma representação alegórica da chegada ao poder dos militares pelo golpe de estado de 1964. A postura do autor em relação a essa interpretação é ambígua. Em alguns casos, Veiga negou veementemente essa leitura: "A hora dos ruminantes estava pronto antes de 1964" (SOUZA, 1990, p. 164). Noutras oportunidades, o escritor entrou em franca contradição, ao reconhecer que:

A hora dos ruminantes é uma alegoria daquilo que estava acontecendo politicamente no Brasil e que eu pensava não ia durar muito. Então, eu termino o livro com uma nota muito otimista: aquilo vai acabar logo, o pessoal vai embora, os ruminantes vão embora [...]. (VEIGA apud RICCIARDI, 1991, p. 69).

O fato é que, para Bernardet e Person, a leitura como alegoria política estava entranhada no processo de adaptação de $A$ hora dos ruminantes, que chamavam de "filme Costa e Silva", em oposição ao seu projeto anterior, $O$ caso dos irmãos Naves, que a dupla havia chamado de "filme Castello Branco" (BERNARDET; PERSON, 2004, p. 9).

$A$ hora dos ruminantes se passa numa ficcional cidade interiorana brasileira: Manarairema recebe a visita de estranhos homens, que se fixam na margem oposta do rio que define os limites da cidade. Trajando uniformes e encarnando a ideia de "progresso", os homens estranhos passam a oprimir a população local, exigindo dela serviços sem nunca deixar claro os motivos que os guiam. Instala-se em Manarairema um ambiente distópico, que é coroado por dois momentos fantásticos de invasões animais. Primeiro são os cães e depois os bois: em ambos os casos, os animais vão chegando gradualmente, e tomando os espaços públicos da cidade, a tal ponto que sua aglomeração impossibilita a circulação dos cidadãos manarairenses, mantendo-os confinados em suas casas. É curioso notar que os animais que invadem a cidade não são monstros ou seres mitológicos bizarros, mas sim animais extremamente comuns no contexto de qualquer cidade brasileira do interior: o que

Memorare, Tubarão, v. 8, n. 1, jan./jun. 2021. ISSN: 2358-0593 
choca a população é justamente o grande número de animais. 0 filme seguiria a mesma história do livro, com algumas alterações, entre elas, o final: enquanto a narrativa de Veiga termina com a partida dos bois e dos homens estranhos, o filme de Person e Bernardet terminaria com a sua permanência. No plano alegórico, essa mudança simbolizaria uma visão mais pessimista por parte dos adaptadores, que acreditavam que a Ditadura Militar duraria por longos anos - como de fato aconteceu.

A literatura de José J. Veiga foi frequentemente associada pela crítica ao realismo mágico latino-americano. Porém, o autor sempre negou uma influência direta:

Confirmo certa influência de Kafka, cuja descoberta acarretou um abalo em minhas concepções. Os outros podem ter influenciado. Afinal, tudo influencia, até o Código Civil, até uma conversa de armazém. Quanto aos hispano-americanos não acho que seriam uma má influência, apenas não os conheci a tempo de ser influenciado por eles em meus primeiros livros. (VEIGA apud SOUZA, 1990).

As questões que trataremos neste artigo são as seguintes: teria o filme de $A$ hora dos ruminantes inaugurado um novo gênero cinematográfico - espécie de realismo mágico cinematográfico brasileiro? Em que medida essa nova estética dialogaria com o gênero literário e cinematográfico - da ficção científica? Discutiremos aqui, a partir de $A$ hora dos ruminantes, a relação entre realismo mágico e ficção científica, apoiando-nos no conceito de distopia.

\section{Ficção científica é sinônimo de tecnologia?}

0 escritor Isaac Asimov define a ficção científica como "o ramo da literatura que trata das respostas do homem às mudanças ocorridas ao nível da ciência e da tecnologia" (ASIMOV, 1984, p. 29). Mas até que ponto a ficção científica está necessariamente atrelada à evolução tecnológica e científica? Não é difícil encontrar exemplos de obras artistas e estéticas, geralmente classificadas como ficção científica, que não apelam necessariamente à presença da tecnologia. Por exemplo, o artista francês Jean Giraud, conhecido pelo seu pseudônimo Moebius, associou uma estética tecnológica a ambientes áridos, com desertos e cânions - vinculados a um contexto de precária evolução tecnológica, como o dos filmes de faroeste. Também podemos considerar exemplos mais recentes: a série televisiva $O$ conto da Aia, baseada na obra homônima de Margaret Atwood, apresenta uma sociedade distópica ultracontrolada, mas não apela para grandes aparatos tecnológicos. Outro exemplo recente é a série de filmes Mad Max, em que não é possível identificar tecnologias futuristas. Em ambos os casos, a atmosfera distópica é bastante presente. Fica evidente que, embora sejam comumente associadas à ficção científica, essas obras não estão vinculadas diretamente às tecnologias futuristas. Ou seja, embora o senso comum costume enxergar a ficção científica como sinônimo de evolução tecnológica, há exceções que mostram que esse vínculo não é obrigatório.

É importante sublinhar que os escritos de José J. Veiga, embora apresentem ambientes interioranos de um país subdesenvolvido, não são necessariamente desvinculados da ideia de avanço tecnológico. Curiosamente, isto pode ser observado em duas obras de Veiga que têm 
uma estrutura bastante semelhante à de $A$ hora dos ruminantes. 0 primeiro livro publicado por Veiga, a coletânea de contos Os cavalinhos de Platiplanto, editado em 1958, traz um conto que serviria de base para A hora dos ruminantes. Trata-se de $A$ usina atrás do morro, narrativa que também mostra uma cidade do interior invadida por estranhos forasteiros uniformizados. Entretanto, no caso do conto, fica claro o motivo da chegada dos forasteiros: são mineralogistas e sua chegada está relacionada com a instalação da usina - fora dos limites da cidade, isto é, "atrás do morro". Além da usina propriamente dita, a tecnologia também é representada pelas motocicletas utilizadas pelos funcionários da usina: uma delas terminará por vitimar o pai do narrador. Ora, é possível observar, portanto, em certas obras de Veiga, o tema recorrente da chegada da tecnologia à cidade interiorana causando desarmonia. Isto está representado de forma ainda mais emblemática na obra de Veiga publicada logo após $A$ hora dos ruminantes, e cuja estrutura é bastante semelhante: em A máquina extraviada, de 1967, os habitantes de uma cidade do interior são surpreendidos pela chegada de um aparato tecnológico cuja origem e função são totalmente desconhecidos. Assim, podemos notar que, em muitas narrativas de Veiga, a tecnologia aparece como um elemento representante do progresso científico, que rompe com a harmonia do ambiente interiorano e arcaico.

0 que dizer então sobre $A$ hora dos ruminantes? Embora a tecnologia não irrompa em nenhum momento da narrativa, o fato é que a ideia de progresso está vinculada aos homens estranhos. É importante observar que a própria crítica da época da publicação chegou a considerar a narrativa como representação da "invasão da tecnocracia" (O Jornal, 1966). Há momentos emblemáticos, como o diálogo entre os habitantes locais em que um deles, o vendeiro Amâncio - que desde o princípio se rende aos homens estranhos - tenta argumentar com os manarairenses que a chegada dos homens representa o progresso, e que aquilo seria positivo: "Eles vieram trabalhar, trazer progresso" (VEIGA, 1966, p. 42). Fica subentendido que é a modernização (representada pela chegada dos forasteiros) o que instaura o ambiente distópico.

Esta fala do personagem Amâncio foi mantida na adaptação de Person e Bernardet, o que mostra que os roteiristas-adaptadores atentaram para este aspecto. Contribui ainda para este argumento a análise de alguns dos documentos anexos, os já mencionados papéis de trabalho que auxiliaram no trabalho de adaptação. Alguns deles se referem a outras obras literárias que aparentemente serviram como apoio para a interpretação da obra. É curioso observar que os adaptadores fizeram uma leitura intertextual que prenuncia parte da crítica de Veiga, ao vinculá-lo a autores e estilos literários aos quais, mais tarde, a crítica também o associaria. É o caso de Franz Kafka: o autor tcheco, como vimos, é uma das únicas influências que Veiga reconhece em sua obra. Como apoio para adaptação de $A$ hora dos ruminantes, Person e Bernardet fizeram uma análise do conto Na colônia penal, no qual encontraram semelhanças com $A$ hora dos ruminantes. Ora, é curioso notar que este conto de Kafka trata justamente de um estranho aparato tecnológico que cumpre a função de executar de forma bárbara a pena imposta aos condenados - é impossível não lembrar aqui dos aparelhos de eletrochoque e outros terríveis aparatos que a

Memorare, Tubarão, v. 8, n. 1, jan./jun. 2021. ISSN: 2358-0593 
repressão da Ditadura Militar utilizava para torturar. A tecnologia, que antes representava o "progresso", passa subitamente a simbolizar a mais absoluta barbárie. 0 tema da tortura é bastante importante para Person e Bernardet, e havia sido o tema de seu filme anterior, $O$ caso dos irmãos Naves, que utilizava uma linguagem alegórica para denunciar a tortura praticada pela Ditadura. Assim, a dupla de realizadores passava do tema da violência física explícita ao tema da violência psicológica e da ameaça.

\section{Distopia: entre ficção científica e realismo mágico}

O contexto político é uma importante chave de leitura que permite aproximar, por meio do conceito de distopia, gêneros aparentemente díspares como o realismo mágico e a ficção científica. A distopia não é exatamente um gênero literário ou cinematográfico: o termo se refere a descrições de sociedades (reais ou ficcionais) que se caracterizam como "utopias negativas" (CHAYT, 2014), o que frequentemente equivale a sociedades próximas do totalitarismo e do autoritarismo. Dada sua proximidade com a ficção científica, a distopia é tema de obras especializadas no gênero, como a Mammoth Encyclopedia of Science Fiction, que a define assim: "Distopias são retratadas frequentemente como estruturas sociais que entraram em colapso sob um fardo ambiental ou regime político"2 (MANN, 2001, p. 477. Tradução nossa). 0 aspecto político parece estar frequentemente vinculado a elas: um dicionário de Ciência Política, The Routledge Dictionary of Politics, define a distopia como "um sistema projetado para enquadrar as piores realidades possíveis da natureza humana e da incompetência política, portanto praticável porém dificilmente desejável"3 (ROBERTSON, 2004, p. 496-7. Tradução nossa). Fica claro, portanto, que nas distopias - do mundo real ou ficcional - frequentemente há um pano de fundo políticosocial; isso explica sua vinculação a regimes políticos específicos. 0 teórico literário Corin Braga, em sua recente tentativa de estabelecer uma "morfologia do gênero utópico", define as distopias em categorias relacionadas à oposição a diferentes ideologias políticas: distopias antifascistas, distopias anticomunistas, distopias anticapitalistas, distopias ecologistas, antirracistas e anticoloniais (BRAGA, 2018, Sumário).

É inegável que as distopias costumam ter um viés político evidente. Nas distopias da ficção científica isso é patente. Porém, o que dizer a respeito do realismo mágico? 0 termo não se refere propriamente a uma estética literária autorreivindicada; ele surge como um instrumento da crítica e do mercado editorial para designar a produção latinoamericana especialmente a partir dos anos 1960. Não por acaso, este período é marcado pela ascensão de ditaduras militares na América Latina, o que certamente ajuda a explicar o fenômeno literário. As distopias do realismo mágico com frequência aparecem diretamente vinculadas ao contexto político. Podemos pensar num romance como Bom dia para os defuntos, de 1970, do peruano Manuel Scorza, que reflete a opressão exercida por uma companhia estrangeira sobre uma

2 "Dystopias are often portrayed as social structures that have collapsed under an environmental burden or political regime" 3 "A dystopia, a system designed to fit with the worst possible realities of human nature and political incompetence, and thus practicable but hardly desirable" 
comunidade de mineiros; apesar do caráter aparentemente fantástico de muitas descrições do romance, o fato é que a obra é diretamente inspirada em um incidente específico: a chegada da companhia estrangeira Cerro de Pasco Corporation a uma região do Peru, e sua interação opressora com a população local. Podemos recordar ainda o romance mais emblemático do realismo mágico, Cem anos de solidão, de 1967, de Gabriel García Márquez, no qual há pelo menos dois momentos marcadamente distópicos: a epidemia de insônia e o massacre promovido pela Companhia Bananeira. Este último episódio também é inspirado diretamente por um evento histórico: o massacre promovido na Colômbia pela companhia estrangeira United Fruit Company. É impossível não pensar também na companhia estrangeira opressora do conto A usina atrás do morro, de José J. Veiga. Estes exemplos do universo ficcional parecem estar atrelados à triste realidade da América Latina, em que companhias estrangeiras oprimem a população de regiões pobres, amparadas pelo mando dos corruptos e autoritários governos militares locais. Vemos, portanto, que o realismo mágico tem em comum com a ficção científica a recorrência de ambientes distópicos, e que este traço está diretamente atrelado à realidade das ditaduras civis-militares que abundaram na América Latina a partir da década de 1960 - precisamente, o momento do boom editorial da literatura latinoamericana e do realismo mágico.

Antes de refletirmos, por meio do conceito de distopia, sobre a relação de $A$ hora dos ruminantes com a ficção científica, é importante perguntar: seria possível falar na existência de uma ficção científica brasileira? Alguns estudiosos já se debruçaram sobre essa questão; não por acaso, muitos deles acabaram esbarrando na relação com a estética do realismo mágico.

Em um ensaio que discute a existência de uma ficção científica brasileira, a professora Elizabeth Ginway considera que "o Brasil, um país frequentemente associado à floresta amazônica, praias tropicais sem fim e às festividades do carnaval, pode parecer um lugar pouco provável para a ficção científica emergir"4 (GINWAY, 2004, p. 13. Tradução nossa) Não apenas o Brasil, mas toda a América Latina, ancorada num passado arcaico, parece se distanciar naturalmente da ficção científica, entendida pelo senso comum como sinônimo de tecnologia. Não é de se estranhar que o termo usado em espanhol, "ciéncia-ficción", seja uma tradução literal do inglês - o que indica que a ficção científica já chegou a nós, latino-americanos, como um gênero importado.

A pesquisadora Maggie Ann Bowers diferencia o realismo mágico da ficção científica pela relação que cada estética constrói com a temporalidade: a ficção científica se projeta como possibilidade futura (num exercício de "futurologia"). Por outro lado, o realismo mágico apresenta um cenário realista indissociável da realidade e da atualidade:

A distinta diferença entre a narrativa de ficção científica e o realismo mágico é que a primeira ocorre num mundo diferente da realidade

\footnotetext{
4 "Brazil, a country often associated with the Amazonian rain forest, endless tropical beaches, and the festivities of carnaval, may seem an unlikely place for science fiction to emerge"
} 
conhecida e seu realismo reside no fato de que podemos reconhecê-lo como possibilidade para o nosso futuro. Ao contrário do realismo mágico, ela não tem um cenário realista que é conhecível em relação a uma realidade presente ou passada. ${ }^{5}$ (BOWERS, 2004, p. 28. Tradução nossa).

Já o professor Alfredo Suppia, estudioso da ficção científica brasileira, observa

A ocorrência de filmes brasileiros típicos de uma abordagem mais regionalizada, em que uma iconografia da ficção científica aparece envolta em elementos de folclore e cultura popular, com tratamento ainda mais fantástico e livre, por vezes remete ao Realismo Mágico latino-americano, porém nem sempre de forma pertinente. (SUPPIA, 2007, p. 335).

De fato, a relação com o folclore e a cultura popular aparece em muitas definições do realismo mágico, entre elas, a do escritor cubano Alejo Carpentier (1949), considerado um dos criadores do termo (embora Carpentier utilize a expressão "real maravilhoso"). No prefácio ao romance $O$ reino deste mundo, considerado um manifesto da estética do realismo mágico, Carpentier associa o conceito ao passado mítico indígena, à influência mística africana e à superstição ibérica.

Naturalmente, o aparecimento de tais características em obras relacionadas à ficção científica abre espaço para a comparação com o realismo mágico - conforme aponta Suppia (2007). Poderia se pensar numa espécie de gênero híbrido, ou em uma configuração latinoamericana da ficção científica em que os elementos do folclore e da cultura popular oral chamam a atenção e remetem o leitor ou espectador imediatamente ao realismo mágico. A alegoria política facilmente associável ao tempo presente reforça essa relação.

\section{O filme $A$ hora dos ruminantes: a invenção de um novo gênero cinematográfico?}

Ao adaptar $A$ hora dos ruminantes para o cinema, teriam Person e Bernardet trabalhado para inaugurar um novo gênero cinematográfico uma espécie de realismo mágico latino-americano? É estranho observar que esta criação seria anterior à influência dos autores hispanoamericanos no cinema, um prenúncio estético - provavelmente relacionado a um contexto político comum, de repressão e autoritarismo. Ou será que poderíamos entender o projeto cinematográfico não filmado de $A$ hora dos ruminantes como um representante da ficção científica que abre mão da tecnologia? Podemos aqui recordar os exemplos da obra em quadrinhos de Moebius, ou de obras audiovisuais como os já citados $O$ conto da Aia e a série de filmes de Mad Max. Este questionamento em si talvez importe mais do que a resposta, que recairia inevitavelmente na escolha de um rótulo redutor, ou na invenção de um novo rótulo, seja pelo cruzamento híbrido das outras duas estéticas, seja pela invenção de uma classificação que, ela própria, passaria a impor suas limitações. Nossa proposta aqui não é responder de forma categórica a esse debate, nem esgotá-lo, mas apenas

\footnotetext{
5 "The science fiction narrative's distinct difference from magical realism is that it is set in a world different from any known reality and its realism resides in the fact that we can recognize it as a possibility for our future. Unlike magical realism, it does not have a realistic setting that is recognizable in relation to any past or present reality"
} 
fornecer elementos para pensar o problema do gênero no projeto cinematográfico não filmado de $A$ hora dos ruminantes.

Para pensar a existência da ficção científica, ou de qualquer outro gênero "importado" para o contexto brasileiro, é preciso levar em consideração a forma como esses gêneros são tratados no mundo dito desenvolvido. A "importação" de gêneros cinematográficos parte de uma falsa premissa de equivalência, desconsiderando elementos especificamente nacionais dos gêneros. 0 pesquisador Rafael de Luna Freire, num estudo intitulado A problemática definição dos gêneros nacionais, explica esta questão:

independente dos conflitos de interpretação, um grande problema é que esse recorte de gênero nacional frequentemente baseia-se numa concepção transcultural dos gêneros. Isto é, assiste-se a filmes policiais estrangeiros (americanos, quase sempre), lê-se livros sobre o que é o gênero policial (em inglês, quase sempre), e depois tenta-se identificar filmes brasileiros que se enquadrem nesse modelo para definir o que é o cinema policial brasileiro. Supondo que o gênero é universal, seria preciso apenas encontrar suas manifestações nacionais. Entretanto esse raciocínio retoma a tradicional e já superada concepção de uma linguagem e técnica cinematográficas universais que podem ser dotadas de uma "cor local". Desse modo, não se leva em conta o fato de que a própria recepção dos gêneros fora de seu contexto de produção implica em diferenças e até num processo de aculturação dos gêneros, uma vez que recepção é sempre reformulação. (FREIRE, 2014, p. 5).

A perspectiva de Freire é interessante na medida em que permite pensar a chegada dos gêneros estrangeiros ao Brasil não apenas pelo prisma do mero acréscimo da "cor local", mas sim como uma reformulação que não é apenas voluntária, mas também inevitável, decorrente da própria incapacidade de transpor de forma exata um gênero para uma realidade tão diferente.

Esta reflexão nos dá ferramentas para pensar o projeto cinematográfico de $A$ hora dos ruminantes como um representante ou da ficção científica brasileira, ou do realismo mágico cinematográfico brasileiro. Um dos primeiros ensaios a tratar sobre o realismo mágico no cinema é On Magic Realism in Film, do pensador marxista Fredric Jameson, publicado em 1986 - portanto, décadas depois do surgimento dos primeiros romances do realismo mágico. 0 ensaio de Jameson traz uma perspectiva reconhecidamente pessoal a respeito do gênero, que não se reduz apenas ao ambiente cultural latino-americano. 0 fato é que, quando analisamos a produção cinematográfica brasileira e latinoamericana contemporânea do projeto de $A$ hora dos ruminantes, percebemos que não há nenhuma obra cinematográfica que possa ser considerada como representante do realismo mágico cinematográfico. As poucas adaptações realizadas àquela altura de autores hispanoamericanos do realismo mágico são malsucedidas, e não chegam a efetivamente transpor o gênero da literatura para o cinema.

Por um lado, isso nos mostra o quanto a iniciativa de $A$ hora dos ruminantes teria sido original naquele contexto. Porém, por outro lado, é indiscutível que a criação de um novo gênero cinematográfico é um desafio para os cineastas e produtores do mundo "subdesenvolvido". Por se tratar de uma arte plenamente imersa no mercado, o processo de adaptação de uma obra literária para o cinema é quase sempre guiado 
por uma motivação simples: o "desejo capitalista de lucrar" (HUTCHEON, 2011, p. 129), nas palavras da teórica da adaptação Linda Hutcheon. Quase sempre, o produtor escolhe apostar em modelos que já obtiveram êxito noutro contexto, obras "já bem-sucedidas financeiramente - a fim de evitar problemas de ordem econômica e a censura" (HUTCHEON, 2011, p. 25).

0 teórico do cinema Andrew Tudor, no compêndio The Film Genre Reader, considera que, dentro do cinema, os gêneros ajudam o espectador e a crítica na compreensão do filme, na medida em que permitem estabelecer relação com outros filmes do mesmo gênero (TUDOR, 2003, p. 3). Transpondo este raciocínio no sentido oposto, é claro que a impossibilidade de encaixar o filme num gênero compromete sua circulação - o que explica, em parte, o obstáculo a uma eventual tentativa de criação do gênero cinematográfico do realismo mágico latino-americano - dificuldade na qual, inevitavelmente, Person e Bernardet esbarrariam.

Se o gênero torna o filme inteligível, então o que dizer do filme que combina mais de um gênero? Por um lado, ele multiplica suas possibilidades de circulação: como se o cineasta estivesse apostando simultaneamente em vários públicos já preexistentes. Ao mesmo tempo, a imposição de um gênero funciona como uma restrição da liberdade criativa dos diretores: o teórico Robert Stam explica como "Os realizadores costumam escolher, ou ser pressionados, a fazer filmes de um certo gênero e 'à moda' de certos diretores" (STAM, 1981, p. 57).

Para tentar pensar a relação do projeto cinematográfico de $A$ hora dos ruminantes com uma possível estética distópica híbrida - meiotermo entre o realismo mágico e a ficção científica - uma contribuição importante pode estar na análise dos documentos anexos ao texto do roteiro cinematográfico. Reproduzimos, a seguir, um importante documento resgatado por nossa pesquisa, em que os adaptadoresroteiristas Person e Bernardet resumem a proposta estética de $A$ hora dos ruminantes:

\section{IDÉIA E REALIZAÇÃO}

Como se pode verificar pelo resumo, a idéia é fazer um FILME-FÁBULA sobre a resistência e a entrega das pessoas aos agentes indeterminados de uma opressão. A moral que se extrai é de que não se deve transigir um mínimo sequer diante da opressão sob pena de se acabar inteiramente dominado por ela. Ao se dar um dedo, perde-se a mão, o braço e assim por diante...

Pelo tratamento dado ao roteiro cinematográfico, superamos totalmente o principal obstáculo que poderia existir com respeito à aceitação do público de um filme em que um grupo de personagens (no caso, os HOMENS ESTRANHOS) não se define logicamente com uma explicação. A não-identificação dos tais homens, além de se constituir inicialmente numa espécie de suspense, cairá a seguir no plano do esquecimento e estimulará a imaginação dos espectadores de melhor nível que encontrarão nisso um motivo a mais para [se interessar pelo] participar do filme.

A partir de um certo momento, o que interessará de modo absoluto ao espectador, não será mais saber quem são e porque motivo os homens oprimem, mas sim verificar como e até que ponto as pessoas vão resistir ou ceder à opressão em si mesma. 
0 tom do filme oscila constantemente entre a comédia mais pura e o drama que frequentemente se insere de modo patético no amolecimento e na resignação de certos personagens.

Além da COR, que terá substancial aproveitamento na realização, pode-se dizer que se trata de um filme espetáculo, onde não faltará música, danças, desfiles, deslumbramento e também uma grande dose de emoção com as vigorosas cenas da invasão dos cachorros e a tomada de Manarairema pelas manadas de bois.

O nível de produção, a clareza e a linearidade da estória, fazem com que o filme atinja o público de todas as categorias, abrindo também uma possibilidade de mercado exterior. (BERNARDET; PERSON, 1967).

A análise deste documento mostra que o problema do gênero de $A$ hora dos ruminantes aponta em distintas direções. Fica claro que este filme que "não se define logicamente com uma explicação" se afasta naturalmente do racionalismo característico das obras de ficção científica, e remete diretamente ao caráter insólito típico da literatura fantástica, fortemente presente no realismo mágico. Enquanto a obra que serviu de base para $A$ hora dos ruminantes - o conto $A$ usina atrás do morro - definia logicamente a aparição dos estranhos forasteiros, esta explicação racional está completamente ausente de $A$ hora dos ruminantes. Vemos, portanto, que embora fosse pensado, até certo ponto, como um filme "comercial" (na medida em que apostava no cinema-espetáculo), $A$ hora dos ruminantes não seria um filme facilmente "inteligível" no sentido tradicional: era um projeto que apostava numa atmosfera insólita - e, até certo ponto, hermética - para reforçar a sensação de estranhamento como efeito estético sobre o espectador. 0 clima insólito instaurado pelo ambiente distópico não seria mera "cor local" elaborada a partir de gêneros distópicos do cinema tradicional, como a ficção científica: $A$ hora dos ruminantes era pensado como uma efetiva reformulação do cinema distópico e insólito, e o fato de se tratar de um gênero novo reforçaria no espectador ainda mais o sentimento de estranhamento.

O filme estimularia a "imaginação dos espectadores" e se apropriaria de um modelo de cinema-espetáculo em que o uso da cor nas cenas fantásticas causaria "deslumbramento"; ora, naturalmente, a ideia de espetáculo cinematográfico remete ao cinema comercial hollywoodiano. 0 interesse dos realizadores pelo "mercado exterior" abre espaço para pensar o problema da hibridez de gênero de $A$ hora dos ruminantes: teriam os realizadores o interesse de exportar o filme para o mercado estadunidense? Nele, ou em mercados estrangeiros marcados pela influência americana, seria importante a relação estabelecida - por meio da distopia - com o gênero da ficção científica, o que poderia auxiliar o espectador e a crítica na compreensão do filme conforme defende o teórico Andrew Tudor (2003). Vale lembrar que as invasões animais (os momentos mais fantásticos do filme) provavelmente recorreriam ao uso de efeitos especiais, o que também aponta para uma aproximação com a ficção científica: o escritor britânico Adam Roberts considera que "ficção científica no cinema é sinônimo de efeitos especiais” (ROBERTS apud SUPPIA, 2017, p. 39). Podemos recordar aqui ainda, de passagem, que parte da crítica de Veiga já havia sugerido a relação com o cinema de ficção científica muito 
antes da nossa pesquisa (a primeira a trazer à luz o projeto cinematográfico de $A$ hora dos ruminantes). É o caso do crítico literário Alcir Pécora, que escreveu:

No caso de 'A usina atrás do morro', o conto mais bem sucedido do conjunto, há curiosamente uma semelhança qualquer com o clima dos filmes B, do cinema americano dos anos 50. (PÉCORA, 2006, p. 13).

Pécora evoca exemplos como " $O$ dia em que a terra parou, $O$ homem de olhos de raio- $x, O$ homem invisível, Invasores de corpos, $O$ homem que encolheu, coisas assim" (PÉCORA, 2014). Para ele, a aproximação é interessante porque

tende a inverter a referência usual da crítica: o que era antiamericano, índice de latinoamericanidade e alegoria da resistência se torna semelhante à ficção científica e ao cinema independente de poucos recursos que havia nos USA, como em outros lugares do mundo. (PÉCORA, 2014, s/p).

A aproximação entre a literatura de Veiga e o cinema distópico feita por Pécora muito antes de o crítico conhecer qualquer tentativa de adaptação da obra de Veiga para o cinema - é um indício do quanto é visível essa espécie de convergência estética entre Veiga e o cinema distópico.

Mas caso o "mercado exterior" ambicionado por Person e Bernardet fosse o latino-americano, é evidente que o diálogo estabelecido seria com um gênero até então estritamente literário, o realismo mágico. Resta ainda a hipótese de que os realizadores Person e Bernardet apostassem naqueles dois mercados exteriores, ou até em outros, como o europeu - no qual, mais tarde, filmes brasileiros alegóricos teriam certo êxito, como é o caso de Macunaíma (1969). É curioso notar que $A$ hora dos ruminantes prenuncia uma produção cinematográfica brasileira alegórica, que se afirmaria na passagem dos anos sessenta para os setenta: podemos recordar os exemplos de Brasil ano 2000, também lançado em 1969, ou O profeta da fome e Pindorama, ambos de 1970. A presença nestes filmes de certo elemento cômico também reafirma $A$ hora dos ruminantes como um precursor desta hibridez de gêneros, algo que os próprios realizadores indicam: "0 tom do filme oscila constantemente entre a comédia mais pura e o drama”. É curioso observar, de passagem, que o elemento cômico também pode ser observado nos primórdios da ficção científica brasileira, conforme nota o pesquisador Alfredo Suppia (2017, p. 31). Naturalmente, estes aspectos alimentam a tese de que $A$ hora dos ruminantes poderia ter inaugurado um gênero cinematográfico novo a partir da sobreposição de aspectos de outros gêneros.

Para concluir, vale lembrar aqui que o projeto cinematográfico de $A$ hora dos ruminantes concebido por Person e Bernardet não é a única tentativa de adaptação da obra para o cinema. 0 cineasta José de Anchieta retomou a ideia de adaptação do livro de Veiga apenas dois anos após a morte de Sergio Person - depois de que o contrato de cessão de direitos autorais para a adaptação da obra perdeu a validade. 0 projeto de Anchieta partiu de um roteiro original, de autoria de Antonio de Pádua - completamente diferente do roteiro de Person e Bernardet. 0 roteiro escrito por Pádua para Anchieta se encontra

Memorare, Tubarão, v. 8, n. 1, jan./jun. 2021. ISSN: 2358-0593 
depositado no acervo da Cinemateca Brasileira em São Paulo - junto com filmagens em 16 milímetros, catalogadas na categoria de "filme inacabado". 0 filme não foi concluído por uma série de imprevistos ocorridos durante e após as filmagens: inundações, desastres naturais, problemas financeiros e jurídicos são alguns dos episódios que (segundo relatos diversos ${ }^{6}$ ) teriam impedido o prosseguimento da filmagem ${ }^{7}$. Para além do caráter anedótico, contribui para a associação de $A$ hora dos ruminantes com a ficção científica o fato de Anchieta ser considerado, pelo estudioso Alfredo Suppia, como um dos mais importantes representantes da ficção científica brasileira: seu filme Parada 88, o Limite de Alerta, lançado em 1977, é considerado um marco no gênero.

Fica claro o quanto o projeto cinematográfico de $A$ hora dos ruminantes de Person e Bernardet dialogaria com diferentes gêneros cinematográficos - especialmente, com a ficção científica e o realismo mágico -, e que este diálogo se daria pelo tema da distopia.

Naturalmente, já havia filmes de ficção científica atecnológicos antes de A hora dos ruminantes: é o caso de Pânico no Ano Zero, de 1962, filme em que o pano de fundo político (neste caso, a paranoia de uma guerra atômica no período da guerra fria) também é notável. É possível supor que $A$ hora dos ruminantes teria despontado como uma vertente brasileira ou latino-americana do subgênero da ficção científica atecnológica. Dentro da leitura alegórica, podemos recordar o argumento de Maggie Ann Bowers (2004): o vínculo com o realismo mágico se daria pela relação com o tempo presente. Manarairema é a completa antítese das metrópoles dos filmes futuristas dos filmes de ficção científica.

Embora se apresentasse como um gênero novo, seu caráter heterogêneo e híbrido talvez permitisse que o filme fosse lido a partir de elementos de outros gêneros artísticos, o que atenuaria o impacto da novidade. É possível especular que o filme teria inaugurado um novo gênero cinematográfico. Trazer à luz hoje o projeto cinematográfico de A hora dos ruminantes permite refletir sobre os rumos que a cultura brasileira poderia ter tomado, naquela passagem entre os anos sessenta e setenta.

\section{Referências}

ASIMOV, Isaac. No mundo da ficção científica. Rio de Janeiro: Francisco Alves, 1984.

BERNARDET, Jean-Claude; PERSON, Luiz Sergio. 0 caso dos irmãos Naves (Chifre em cabeça de cavalo). Argumento e Roteiro. São Paulo: Imprensa Oficial, Coleção Aplauso. Fundação Padre Anchieta, 2004.

\footnotetext{
${ }^{6}$ Além de relatos verbais do diretor da cinemateca do Museu de Arte Moderna do Rio de Janeiro, Hernani Heffner e da cineasta Regina Jehá, que foi casada com Luiz Sergio Person, foram consultados artigos em periódicos como: 'Walter Carvalho, o outro', publicado em Almanaque da Rosário, 17 de outubro de 2012. \& PONTES, José Carlos. 'Roliúde caipira' in Jornal Oquê, 14 de Março de 2017.

7 O set contava com fotografia de Walter Carvalho e direção de produção de Carlos Dália, e o elenco teria nomes como Jofre Soares. A despeito deste fracasso em 1978, sabemos que o projeto cinematográfico de $A$ hora dos ruminantes foi retomado pelo mesmo cineasta, conforme indica uma carta de 1998 da produtora Vera Cruz pedindo de José J. Veiga uma declaração de intenção de ceder os direitos do livro - documento encontrado por nossa pesquisa no espólio do escritor. Porém, tampouco nesta segunda tentativa, o filme foi concluído.
} 
BERNARDET, Jean-Claude; PERSON, Luiz Sergio. A hora dos ruminantes. Roteiro cinematográfico e anexos. Material doado por Jean-Claude Bernardet ao acervo da Cinemateca Brasileira. São Paulo, 1967.

BOWERS, Maggie Ann. Magic(al) Realism. Routledge, 2004.

BRAGA, Corin. Pour une morphologie du genre utopique, Classiques Garnier, 2018.

CHAYT, Eliot Briklod. Disaster, Dystopia, and Exploration: Science-Fiction Cinema 1959-1971. Tese de Doutorado em Filosofia. University of Texas at Austin. Maio de 2014.

FREIRE, Rafael de Luna. A problemática definição dos gêneros nacionais. In: Filme Cultura, n. 61, novembro e dezembro 2013 a janeiro de 2014, p. 15.

GINWAY, Elizabeth. Brazilian Science Fiction: Cultural Myths and Nationhood in the Land of the Future, Bucknell University Press, 2004.

HUTCHEON, Linda. Uma teoria da adaptação. Editora UFSC, Santa Catarina, 2011.

JAMESON, Fredric. On Magic Realism in Film. In: Critical Inquiry, n. 12, inverno de 1986. The University of Chicago.

MANN, George. 'Dystopia' in The Mammoth Encyclopedia of Science Fiction. Londres: Robinson, 2001.

O Jornal. Jornal Literário. Rio de Janeiro, 23 de dezembro de 1966.

PÉCORA, Alcir (Org.). Apresentação. In: Lembranças do presente - o conto contemporâneo. Lisboa: Cotovia, 2006.

PÉCORA, Alcir. Depoimento concedido por e-mail em 27 de fevereiro de 2014.

RICCIARDI, Giovanni. Auto-retratos. São Paulo: Martins Fontes, 1991.

ROBERTSON, David. Utopianism in The Routledge Dictionary of Politics. Londres: Taylor \& Francis, 2004.

SOUZA, Agostinho Potenciano, Um Olhar Crítico sobre o nosso tempo: uma leitura da obra de José J. Veiga. Campinas: Editora Unicamp, 1990.

STAM, Robert. 0 espetáculo interrompido - Literatura e cinema de desmistificação. Rio de Janeiro: Paz e Terra, 1981.

SUPPIA, Alfredo Luiz Paes de Oliveira. Limite de Alerta! Fiç̧ão Científica em Atmosfera Rarefeita: Uma introdução ao estudo da FC no cinema brasileiro e em algumas cinematografias off- Hollywood. Tese de Doutorado (Instituto de Artes) Universidade Estadual de Campinas, Campinas, 2007.

SUPPIA, Alfredo. Nas veredas do tempo e a contrapelo da história: por um cinema brasileiro de ficção científica. In: ALMEIDA, Rodrigo \& MOURA, Luís Fernando (org.), Brasil Distópico, Ponte Produções, Rio de Janeiro, 2017, p. 39.

TUDOR, Andrew. Film genre reader III. Editado por Barry Keith Grant. University of Texas Press, 2003. 
VEIGA, José J. A hora dos ruminantes, Civilização Brasileira, Rio de Janeiro, 1966.

Artigo enviado em: 10/05/2021. Aprovado em: 21/06/2021. 